\title{
METHODOLOGICAL MODEL FOR ENHANCEMENT OF THE ECOLOGICAL COMPETENCES OF STUDENTS THROUGH SUSTAINABLE WASTE MANAGEMENT
}

\author{
Bogdan Nikolov ${ }^{1}$, Gergana Stankova ${ }^{2}$, Atidzhe Tabak ${ }^{3}$, Milena Kateva ${ }^{4}$, \\ Radina Shamburova $^{5}$, Polina Dzhambazova ${ }^{6}$, Slaveya Petrova $^{7}$, Vanya Naydenova $^{8}$, \\ Delka Karagyozova-Dilkova ${ }^{9}$
}

\begin{abstract}
The idea and practice of separate waste collection is widespread in Europe as an effective way of building public awareness of environmental responsibility. The study covers activities on the most current environmental topics: sustainable development, municipal waste, recycling, composting. The project provides opportunities for cooperation and interaction between students in a team organisation of cognitive activity, the implementation of active student learning, and constructivist design of training, which will increase the practical orientation of the acquired knowledge and competences. The project aims at developing an innovative curriculum, curriculum content, methodological model, and didactic materials for the education of high school students and to increase their environmental competence in sustainable waste management at school and in their households. As a result of the training activities following Kolb's cycle, the participants in the study have changed their behaviour with the tendency to reduce the wastes amount and the use of disposable packages.
\end{abstract}

UDC Classification: 37.04, DOI: https://doi.org/10.12955/pns.v1.125

Keywords: sustainable development, school, training, ecology

\section{Introduction}

Basically, we all share common environmental protection needs, goals, and objectives. Responsibility for the fate of nature is fostered, and childhood is the most appropriate start to a lasting upbringing of environmental responsibility. The citizen's environmental commitment starts at a young age, and his thinking and development should be part of the educational process in all stages of the modern education system.

The modern world is in a situation of rapid change in civilisational values. Globalisation, as well as the development of information and communication technologies, have a significant impact on the priorities, goals, and paradigms of education, forms, and methods of training. In the process of learning, the student needs to seek, discover, apply knowledge to solve problems constantly. The concept of lifelong learning is being established. Teachers and methodologists are actively working towards this direction. This concept also applies to biological culture and competence. Although the breakthroughs in biology are multiplying at a steady pace, global environmental problems are deepening. The phenomena are complex and require skills for team discussion and teamwork, original ideas and solutions, critical appraisal, the motivation of students for active learning activities.

Environmental education is a priority in the education system. It not only plays a crucial role in biological education but also in many other natural and humanities disciplines. Ecological education is the most correct and secure path to the future, which guarantees a harmonious relationship between man,

\footnotetext{
${ }^{1}$ Plovdiv University „Paisii Hilendarski“, Faculty of Biology, Department of Ecology and Environmental Conservation, Plovdiv, Bulgaria, nikolov81bg@yahoo.com

2 Plovdiv University „Paisii Hilendarski“, Faculty of Biology, Department of Botany and Teaching Methods in Biology, Plovdiv, Bulgaria, g_stankova@abv.bg

${ }^{3}$ Plovdiv University „Paisii Hilendarski“, Faculty of Biology, Plovdiv, Bulgaria, Bachelor student, tabakatice@abv.bg

${ }^{4}$ Plovdiv University „Paisii Hilendarski“, Faculty of Biology, Plovdiv, Bulgaria, Bachelor student, katevamilena@abv.bg

${ }^{5}$ Plovdiv University „Paisii Hilendarski“, Faculty of Biology, Plovdiv, Bulgaria, Bachelor student, radina973@gmail.com

${ }^{6}$ Plovdiv University „Paisii Hilendarski“, Faculty of Biology, Plovdiv, Bulgaria, Bachelor student, poli_djambazova@abv.bg)

${ }^{7}$ Plovdiv University „Paisii Hilendarski“, Faculty of Biology, Department of Ecology and Environmental Conservation, Plovdiv, Bulgaria, sl.petrova@abv.bg

${ }^{8}$ Plovdiv University - „Lyuben Karavelov“ Branch, Department of Pedagogy, Kardzhali, Bulgaria, vanianay@abv.bg

${ }^{9}$ Plovdiv University „Paisii Hilendarski“, Faculty of Biology, Department of Botany and Teaching Methods in Biology, Plovdiv, Bulgaria, dkarag@abv.bg
} 
nature, and society (Vakleva, 2011). Through ecological education, an ecological culture is formed, which is expressed in ecological assessment and consciousness, ecological attitude, environmental and constructive behaviour. The value aspect in the ecological culture of the modern individual is the love of nature as one of the most important goals of education (Sterling \& Cooper, 1992).

Environmental education is a long-term process that aims at raising awareness of environmental issues, absorbing knowledge, forming attitudes, values, and a sense of responsibility for the rational use of natural resources, as well as encouraging action on nature conservation and sustainable development (Uzzel, 1999).

The aim of the present study is dictated by the priorities of school education, namely, the training of students through active learning, interaction, and team organisation of learning activities, the acquisition of key competences. The experiment covers activities on the most current environmental topics: sustainable development, municipal waste, recycling, composting.

\section{Literature review}

The idea and practice of separate waste collection is widespread in Europe as an effective way of building public awareness of environmental responsibility. As an activity that takes place daily and affects the routine aspects of our lives, it helps to establish permanent patterns of behaviour. Waste separation sharpens people's sensitivity to environmental problems. According to many researchers of social phenomena, waste separation initiates the learning process, forcing people to adapt their daily activities to environmental norms and to encourage them with their actions to feel significant and able to contribute to environmental protection.

The behaviour of the residents of Exeter, U.K., towards waste management (the three R) was studied by Stewart Barr (2007) using its original conceptual framework. He found that the most significant factors determining this kind of human behaviour, were the environmental values, situational characteristics, and individuals' psychology.

The government, the Non-governmental organisations (NGOs), and the citizens in general, should take place in addressing sustainable waste management. The governments' responsibilities are mainly related to establish an appropriate law regulation and to assure the technical details for waste collection, transport, and treatment. The principal engagements of the NGOs are in the aspect of various campaigns and activities in support of the environment and providing technical expertise to municipalities (Kamaruddin et al., 2013). Other authors point out that the NGOs' role is also in the field of collecting waste for deprived communities and initiating recycling projects (Colon \& Fawcett, 2006), as well as focusing on the public awareness towards sustainable waste management (Shekdar, 2009). However, NGOs' role in the process of sustainable waste management is still not clearly pointed out (Davies, 2007).

Many campaigns by state and municipal institutions, as well as by the NGOs, which are implemented on the territory of some schools, are relatively instantaneous, without leading to a lasting increase in the environmental competences and habits of the students. Despite some good practices in a small number of Bulgarian schools, there have not yet been developed and tested didactic models on the issue of separate waste collection at school and at home to be implemented in the primary education system.

\section{Data and methodology}

Our working hypothesis is as follows: If a sustainable waste management training is planned and implemented through a proactive approach, it will increase students' environmental competences. To test the working hypothesis, theoretical analysis, and didactic experiment are applied as the main methods in the pedagogical research. Additionally, other methods are used in the research process, which complement each other - pedagogical observation and analysis of practical experience, questionnaires with students, statistical evaluation of the results.

Based on the contemporary theoretical concepts of pedagogy, didactics, and psychology, our team developed an innovative methodological model. The foundations of constructivist theory applied in experimental training are based on the following constructs: $i$ ) Knowledge is based on the student's personal experience; ii) Knowledge is built individually and socially; iii) Knowledge is used to apply it to the student's life; $i v$ ) The main training methods are real-time observation and practical work (Driscoll, 2000). 
The cognitive activity of students is based on the theory of learning by experience and is carried out in the cycle of D. Kolb (Kolb, 1976). The innovative methodological model includes some problems for active learning by each thematic lessons. Each problem is carried out in small groups (8-10 students); after that, the team presents the results, and a group discussion is held. The problems for exploring in each thematic lesson are divided into 4 stages following the Kolb's learning cycle (experience, reflection, the conceptualisation of experience, application, or planning of the next experience). By this model, the students are involved in the active construction of their knowledge, instead of receiving provided information (Karagyozova-Dilkova, 2007).

Two questionnaires, "My ecological footprint" with an equal number of questions (15), are developed to account for the results of the training conducted on the innovative methodological model. The first questionnaire was made before the training in order to determine the level of knowledge and competence in the problem up to the time of the survey. The second questionnaire was conducted after the training in order to take into account the effectiveness of the methodological model. The questions are designed in such a way that they allow analysing both the ecological competences of the students (knowledge construct), the attitudes (attitude construct), and behaviour (behaviour construct) of the students and their families towards separate waste collection (Vassileva, 2013).

Almost 100 students of the 11-12 years' age were involved in the first stage of the innovative methodological model's approbation. They study in six different schools from three different settlements - the city of Plovdiv, the town of Kazanluk, and the village of Krumovo. The training was realised by some Bachelors students from the Faculty of Biology at the Plovdiv University "Paisii Hilendarski" (Plovdiv, Bulgaria).

\section{Results and Discussion}

In the course of the project, an innovative curriculum program was developed "Wastes and their treatment," whose thematic content is divided into four lessons: Waste definition and classification, Waste treatment, Recycling process, Composting process. For each topic, the planned learning activities and the expected results of the study are described. Worksheets have been developed for each of the lessons to allow for an active approach to student learning. The content of all lessons was structured following environmental topics, enabling environmental education through a proactive approach.

The first step in the analysis of the results of the experiment was to assess the change in the environmental competences of the studied students, which occurred as a result of the training. To this end, a comparison was made between the answers to the Questionnaire 1 (before) and the answers to the same questions at the Questionnaire 2 (after), with the data presented in Fig. 1. When regarding the responses of the question "My waste today could fit in a small box / small trash bin / big trash bin" (attitude construct), it was evident that the respondents from the two bigger settlements have significantly higher wastes amount before training $(\mathrm{p}<0.05)$. After the course, we found reducing the waste quantity in all groups of students, mostly expressed at the two smaller settlements where a reduction of $64 \%$ (Kazanluk) and $25 \%$ (Krumovo) was proven.

In analysing the answers at the entry-level to the question "I repeatedly use items instead of throwing them away: yes / in most cases / no" (behaviour construct), we did not observe significant differences in the behaviour of the students from Plovdiv and Krumovo, the tendency being about $16-25 \%$ of respondents have long-term habits for rational use of resources, and the other $42-52 \%$ - in most cases (Fig. 1). The analysis of the results of the entry-level of the students from the town of Kazanlak showed a very significant difference in the behaviour compared to the other two groups - the proportion of students who repeatedly use items was $43 \%$, i.e., nearly 2 times higher $(\mathrm{p}<0.05)$. After the training on the methodical model created, we reported a positive change in behaviour of all the three groups, revealing an improvement in the reusable behaviour within the range of 10-20\%.

Impressive results were also obtained regarding students' knowledge of the way that plastic waste can be disposed of in a yellow container (knowledge construct) (Fig. 1). A significant lack of knowledge was proved for the students from Kazanluk compared to the students from the other two settlements ( $\mathrm{p}<0.05$ ). Only 64\% of the respondents were informed that this waste should be emptied of their contents and crushed, against $84 \%$ in the city of Plovdiv and $92 \%$ in the village of Krumovo. The second survey showed that the effectiveness of training in this group was the highest, showing a 29\% increase in correct answers, and overall the share was $93 \%(\mathrm{p}<0.05)$. Although in the groups of the other two cities, the 
correct answers were $93 \%$ and $100 \%$ respectively, the proven increase in competencies is in the order of $8-9 \%$ and has no statistical significance.

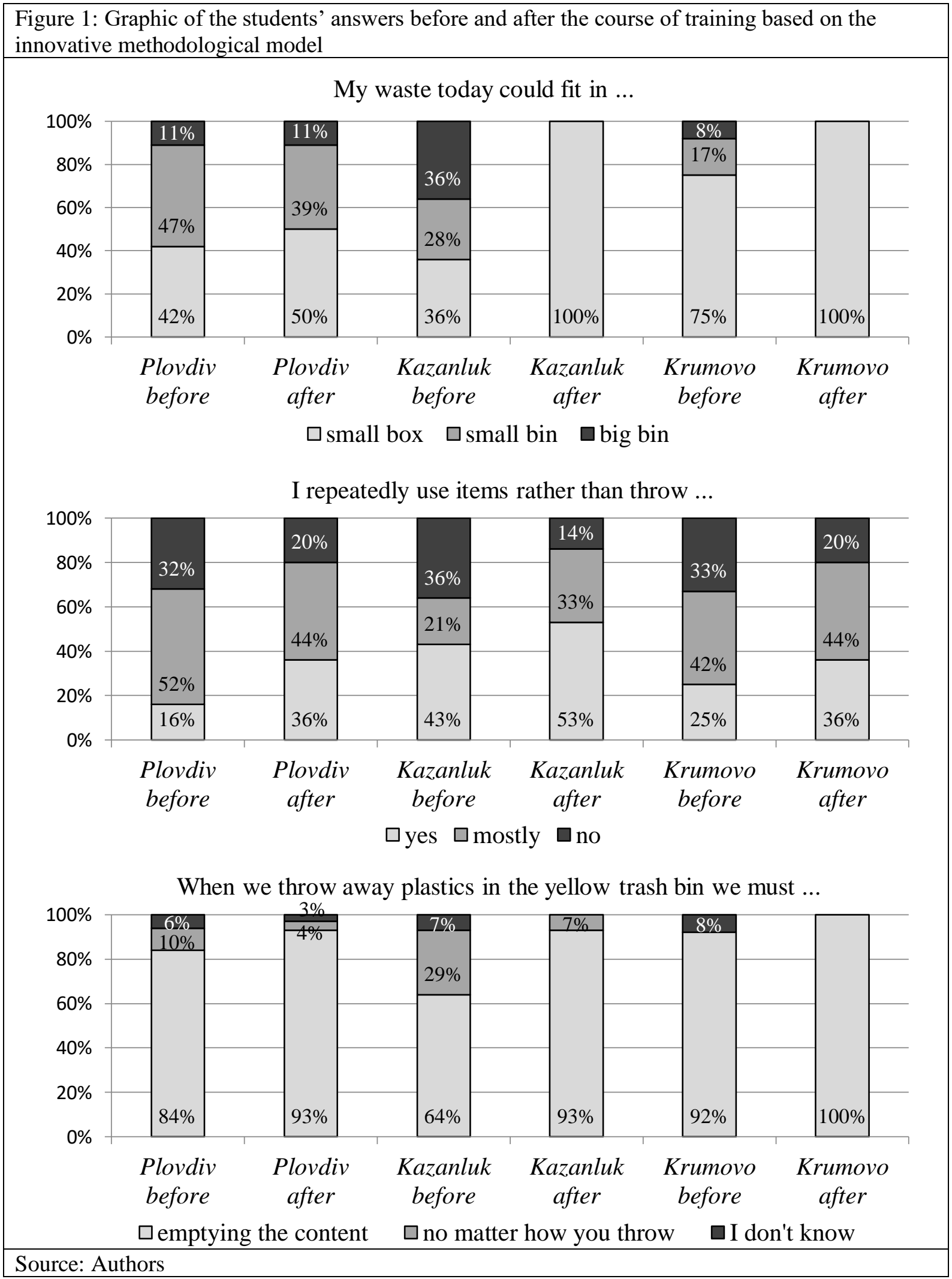

\section{Source: Authors}

The last step of the result's analysis involved a comparison between the starting level of the students from the three schools, which takes into account the real expression of three constructs (knowledge, attitude, and behaviour) of the students as a result of the training carried out according to the proposed didactic model. These analyses took into account not only the quantitative data from the baseline but 
also the differences in the starting level - the baseline level in order to objectively evaluate the effectiveness of the training and test the working hypothesis.

Based on the attitude construct, we found that the working hypothesis was confirmed for $66.7 \%$ of the students from the village of Krumovo, who had less involvement in the waste problem before the training $\left(\chi^{2}=2.941\right)$, for $73,3 \%$ of the students from the city of Plovdiv $\left(\chi^{2}=1.475\right)$ and for $88,9 \%$ of the students from the town of Kazanluk $\left(\chi^{2}=3.524\right)$, who showed less interest in waste reducing before training $(\mathrm{p}<0.05)$. By the behaviour construct, the working hypothesis was confirmed for nearly 15$20 \%$ of the students from all three settlements who had not had long-term habits for nature conservation and rational use of resources by the time of training $\left(\chi^{2}=2.069-4.702\right)(p<0.05)$. This was the construct with the lowest positive change from the three studied. According to the knowledge construct, we found that the working hypothesis was confirmed for $69 \%$ of the less knowledgeable students in Plovdiv $\left(\chi^{2}=\right.$ 1.792 ), for $78 \%$ of the less familiar with the problem students from Krumovo $\left(\chi^{2}=0.964\right)$, and $82 \%$ of the students in the town of Kazanluk who showed a low level of knowledge $\left(\chi^{2}=0.773\right)(p<0.05)$.

As a summary of the statistical analysis conducted, we can point out that the students from Plovdiv had a higher background level of knowledge on sustainable waste management. Although after the training they gave the best results, the efficiency of our training (measured by attitude and behaviour constructs) was lower than in the smaller settlements Kazanlak and Krumovo. This fact underscores the need to target training, especially towards the enhancement of the ecological competences and building of the pro-ecological behaviour.

\section{Conclusion}

The study covers activities on the most current environmental topics: sustainable development, municipal waste, recycling, composting. The project provides opportunities for cooperation and interaction between students in a team organisation of cognitive activity, the implementation of active student learning, and constructivist design of training, which will increase the practical orientation of the acquired knowledge and competences. As a result of the training activities following Kolb's cycle, the participants in the study have enhanced their ecological competences and have changed their behaviour with a tendency to reduce the wastes amount and the use of disposable packages.

\section{Acknowledgements}

This research work was carried out with the support of the Scientific Fund at the Plovdiv University „Paisii Hilendarski“" by contract SP19BF008, managed by Assoc. Prof. Delka Karagyozova-Dilkova.

\section{References}

Barr, S. (2007). Factors Influencing Environmental Attitudes and Behaviors: A U.K. Case Study of Household Waste Management. Environment and Behavior, 39(4), 435-473.

Davies, A. (2007). A wasted opportunity? Civil society and waste management in Ireland. Environmental Politics, 16, 52-72. Driscoll, M. (2000). Psychology of Learning for Instruction. Boston: Allyn \& Bacon

Kamaruddin, S.M., Pawson, E., \& Kingham, S. (2013). Facilitating Social Learning in Sustainable Waste Management: Case study of NGOs involvement in Selangor, Malaysia. Procedia - Social and Behavioral Sciences, 105, 325-332.

Karagyozova-Dilkova, D. (2007). Person-oriented strategies in biology education. Plovdiv, Bulgaria: Plovdiv University Publishing House.

Shekdar, A.V. (2009). Sustainable solid waste management: An integrated approach for Asian countries. Waste Management, $29,1438-1448$

Sterling, S., \& Cooper, G. (1992). In touch: environmental education for Europe. Surrey, UK:WWF, Panda House Uzzel, D. (1999). Education for environmental action in community: new roles and relationships. Cambridge Journal of Education, 29(3):397-414.

Vakleva, Z. (2011). Environmental education - a vision for the future. Plovdiv, Bulgaria: Macros Publishing House. Vassileva, E. (2013). Models of sustainable consumption of individual consumers and households in Bulgaria. Sofia, Bulgaria: Publishing House 